\title{
Impact of corticotropin-releasing hormone on gastrointestinal motility and adrenocorticotropic hormone in normal controls and patients with irritable bowel syndrome
}

\author{
S Fukudo, T Nomura, M Hongo
}

\begin{abstract}
Background-Corticotropin-releasing hormone (CRH) plays a key role in modulating intestinal motility in stressed animals.

Aims-To evaluate the effect of CRH on intestinal motility in humans and to determine whether patients with irritable bowel syndrome (IBS) have an exaggerated response to CRH.

Subjects-Ten IBS patients diagnosed by Rome criteria and 10 healthy controls. Methods-CRH (2 $\mu \mathrm{g} / \mathrm{kg})$ was intravenously administered during duodenal and colonic manometry and plasma adrenocorticotropic hormone (ACTH) was measured by radioimmunoassay.

Results-CRH induced motility of the descending colon in both groups $(p<0.001)$ and induced greater motility indexes in IBS patients than in controls $(p<0.05)$. CRH produced duodenal phase III motor activity in $80 \%$ of the subjects and duodenal dysmotility in $40 \%$ of IBS patients. Abdominal symptoms evoked by CRH in IBS patients lasted significantly longer than those in controls $(p<0.05)$. CRH induced significant increases in plasma ACTH levels in both groups $(p<0.001)$ and produced significantly higher plasma ACTH levels in IBS patients than in controls $(p<0.001)$.

Conclusion-Human intestinal motility is probably modulated by exogenous CRH. The brain-gut in IBS patients may have an exaggerated response to CRH. (Gut 1998;42:845-849)
\end{abstract}

Department of Psychosomatic

Medicine

S Fukudo

T Nomura

Department of Comprehensive Medicine, Tohoku University School of Medicine, Sendai, Japan

M Hongo

Correspondence to: Dr S Fukudo, Department of Psychosomatic Medicine,

Tohoku University School of Medicine, 1-1 Seiryo-machi, Aoba-Ku, Sendai 980-8574, Japan.

Accepted for publication 19 January 1998 the duodenal migrating motor are exaggerated in IBS patients. $^{34}$ Wrap restraint stress in rats is also reported to facilitate colonic motility and to inhibit small intes- tinal motility. ${ }^{5}{ }^{6}$ These phenomena in rats are mimicked by intracerebroventricular ${ }^{6-9}$ or intravenous $^{9}$ administration of corticotropin releasing hormone (CRH) and are blocked by the CRH antagonist, $\alpha$ helical $\mathrm{CRH}_{9-41}{ }^{6-9}$ Stress induces anxiogenic behaviour in rats and intracerebroventricular administration of $\mathrm{CRH}$ mimics the behavioural changes under stress. ${ }^{10}$ Furthermore, intravenous administration of $\mathrm{CRH}$ decreases slow wave sleep in humans. ${ }^{11}$

These findings led us to hypothesise that $\mathrm{CRH}$ plays a major role in the stress response of humans, both normal subjects and IBS patients. The purpose of this study was to determine whether intravenous administration of $\mathrm{CRH}$ affects human gastrointestinal motility and whether CRH discriminates physiological responses in normal control subjects from those in IBS patients.

\section{Methods}

SUBJECTS

Ten normal healthy volunteers and 10 IBS patients were studied. Both groups consisted of five men and five women. Ages (controls: 20.7 (0.5) years versus IBS: 23.8 (3.6) years) and body mass indexes (controls: $21.8(0.6)$ versus IBS: 21.0 (1.1)) were almost matched. Control subjects were paid volunteers who had no symptoms or history of major diseases. IBS patients were diagnosed by the Rome criteria ${ }^{12}$; they also had recurrent abdominal pain with alternating diarrhoea and constipation for more than two years, with temporal exacerbation of these symptoms by psychosocial stress. No patient had a history of abdominal surgery or evidence of organic disease by diagnostic studies including blood tests, urinalysis, stool analyses, plain $x$ ray film of the abdomen, barium enema, colonoscopy, and the lactose tolerance test. Because of the unstable bowel habit, our patients were not classified into two subgroups of diarrhoea or constipation. This notion is supported by an earlier study in which these symptoms of IBS fell into the same principle component in multivariate analysis. ${ }^{13}$ Informed consent was obtained from all subjects and this study was approved by the Tohoku University Ethics Committee.

CANNULATION AND RECORDING ASSEMBLIES Intestinal motility was recorded by previously reported methods. ${ }^{4}$ In brief, an assembly consisting of three transducers (Sentron, Amsterdam, Netherlands) was inserted into the descending colon using colonoscopy at 08.30. On the evening before colonoscopy, the 
Table 1 Influence of CRH on patterns of gastrointestinal motility, abdominal symptoms, and duodenal $\mathrm{pH}$

\begin{tabular}{|c|c|c|c|}
\hline & $\begin{array}{l}\text { Controls } \\
(n=10)\end{array}$ & $\begin{array}{l}\text { Patients with IBS } \\
(n=10)\end{array}$ & $p$ Value \\
\hline \multicolumn{4}{|l|}{ Latency of evoked motility (min) } \\
\hline Colon & $3.0(0.6)$ & $2.8(0.8)$ & NS \\
\hline Duodenum & $3.1(0.5)$ & $3.0(0.9)$ & \\
\hline \multicolumn{4}{|c|}{ Occurrence of phase III during first $15 \mathrm{~min}$ of } \\
\hline Baseline (n) & 2 & 1 & NS \\
\hline $\mathrm{CRH}$ & $8^{\star}$ & $8^{\star}$ & NS \\
\hline \multicolumn{4}{|l|}{ Clustered contractions or other dysmotility } \\
\hline \multicolumn{4}{|l|}{ Abdominal pain or discomfort during } \\
\hline Baseline (n) & 0 & 0 & NS \\
\hline $\mathrm{CRH}(\mathrm{n})$ & 2 & 6 & NS \\
\hline \multicolumn{3}{|l|}{ Duration of abdominal pain or discomfort } & $0.05 \ddagger$ \\
\hline \multicolumn{4}{|l|}{ Area below pH 7.0} \\
\hline Baseline (n) & $-0.84(0.17)$ & $-0.85(0.13)$ & NS \\
\hline $\mathrm{CRH}(\mathrm{n})$ & $-0.95(0.24)$ & $-0.68(0.12)$ & NS \\
\hline
\end{tabular}

Data are presented as mean (SE) or number of cases (n).

${ }^{\star} \mathrm{p}<0.05$ significant variation by McNemar's test; $\nmid \mathrm{p}<0.05$ significant difference by Fisher's exact test; $\neq \mathrm{p}<0.05$ significant difference by the Mann-Whitney U test.

$\S$ Three cases with clustered contractions and a case with retrograde phase III-like contractions.

subjects ingested a solution composed of 125 $\mathrm{ml}$ of magnesium citrate $(13.6 \%)$ and $2.5 \mathrm{mg}$ of sodium picosulphate to lessen the faecal effluent. Based on an earlier report, ${ }^{14}$ this bowel preparation was unlikely to affect the colonic motility. Another assembly with three transducers and a pH sensor (Monocrystant Antimony, Synectics, Stockholm, Sweden) was inserted transnasally into the third portion of the duodenum. The position of catheters without major drift were certified by fluoroscopy with $x$ ray before and after the study. These catheters consisted of three sensors $5 \mathrm{~cm}$ apart. The pressure at the following points (distance from the mouth or anus) was measured: duodenal bulb $(60 \mathrm{~cm})$, proximal second portion of the duodenum $(65 \mathrm{~cm})$, distal second portion of the duodenum $(70 \mathrm{~cm})$, descending colon $(60 \mathrm{~cm})$, proximal sigmoid colon $(55 \mathrm{~cm})$, and mid sigmoid colon $(50 \mathrm{~cm})$. The sensors were tip transducers made from a semiconductor. The measuring range of the sensors was from $-50 \mathrm{~mm} \mathrm{Hg}$ to $1000 \mathrm{~mm} \mathrm{Hg}$, with $-3 \mathrm{~dB}(0-180 \mathrm{~Hz})$ of the frequency property. The $\mathrm{pH}$ sensor was located in the third portion of the duodenum $(75 \mathrm{~cm})$. A pneumogram was taken from a pick up belt around the
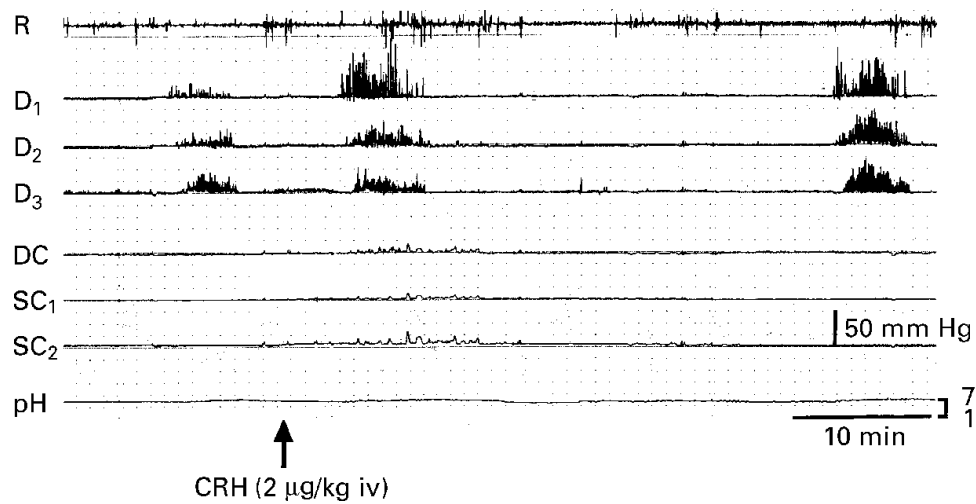

Figure 1 Manometric recordings of a normal control subject. $R$, respiration; D1, duodenal bulb/antrum; D2, proximal second portion of the duodenum; D3, distal second portion of the duodenum; DC, descending colon; SC1, proximal sigmoid colon; SC2, mid sigmoid colon; $p H$, duodenal $p H$. Note the fine colonic contractions after intravenous $C R H$. Even though CRH was injected during duodenal phase I immediately after phase III at the end of baseline, administration of CRH evoked duodenal phase III. chest. A Teflon cannula was inserted into an arm vein for blood sampling and saline was infused at a speed of $0.5 \mathrm{ml} / \mathrm{min}$. Two pressure catheters, the $\mathrm{pH}$ sensor, and pick up, were connected to an analogue to digital converter (PC-Polygram, Synectics). The analogue signals were sampled at $8 \mathrm{~Hz}$, digitised, entered into a computer (PC-9801 ES, NEC, Tokyo, Japan) via fibreoptic cable, and stored on magnetic hard disk for later analysis.

\section{EXPERIMENTAL DESIGN}

The subjects lay on a bed at 11.00 after the above procedures were completed. Respiration, duodenal pressure, colonic pressure, and duodenal $\mathrm{pH}$ were monitored for 240 minutes. The subjects were instructed to inform the investigators of the beginning and the end of abdominal symptoms. These symptoms were notable on the motility data record. The experiment consisted of the three periods: the initial 60 minutes for adaptation; the following 60 minutes for baseline; and the last 120 minutes for effect of CRH. Saline $(20 \mathrm{ml})$ was injected at 12.00. Human CRH (Peptide Institute, Osaka, Japan) was dissolved in $20 \mathrm{ml}$ of saline immediately before the experiment and $2 \mu \mathrm{g} / \mathrm{kg}$ was injected intravenously within one minute at 13.00. This is the dose which alters gastrointestinal function in animals ${ }^{9}$ and increases plasma adrenocorticotropic hormone (ACTH) secretion to stress levels with detectable plasma CRH in humans. ${ }^{15}$ Furthermore, blood pressure is known to be unchanged at this dose. ${ }^{16}$ Blood (5 $\mathrm{ml}$ ) was drawn from the cannula placed in the vein at $0,15,30,60,90$, and 120 minutes after $\mathrm{CRH}$ injection. Blood was collected into two tubes: one with EDTA $(1 \mathrm{mg} / \mathrm{ml})$ as the first reagent for ACTH assay, and the other without reagent for cortisol assay. Plasma and serum were obtained by centrifugation of the samples at $3000 \mathrm{rpm}$ for five minutes, frozen, and stored at $-45^{\circ} \mathrm{C}$ for later analysis.

\section{DATA ANALYSIS}

A colonic motility index was calculated by measuring the area under the pressure records for each 15 minute period using a computerised planimeter (Gastrosoft). ${ }^{17}$ Motility index was calculated as follows: motility index $=100$ $(\%) \times$ area under the curve $(\mathrm{mm} \mathrm{Hg} / \mathrm{sec}) /(15 \times$ $60 \mathrm{sec}$ ). Duodenal motility was analysed by duration of three phases: phase I, period of quiescence; phase II, period of irregular contractile activity; and phase III, period of regular contractile activity with at least three minutes of uninterrupted phasic pressures at the maximum frequency of 11-13 per minute of MMC. ${ }^{18}$ The timing of CRH injection was in phase I or II at the end of the baseline.

Patterns of duodenal dysmotility were defined and analysed as follows. Clustered contractions were groups of phasic waves, occurring at a rate of 10-12 per minute and lasting overall five minutes or longer; individual waves had amplitudes of at least $15 \mathrm{~mm} \mathrm{Hg}$, often with some tonic elevation of the basal pressure. ${ }^{19}$ Individual clusters were preceded and followed by at least 30 seconds of quiescence. ${ }^{19}$ Retrograde phase III-like contractions were regular contractile 


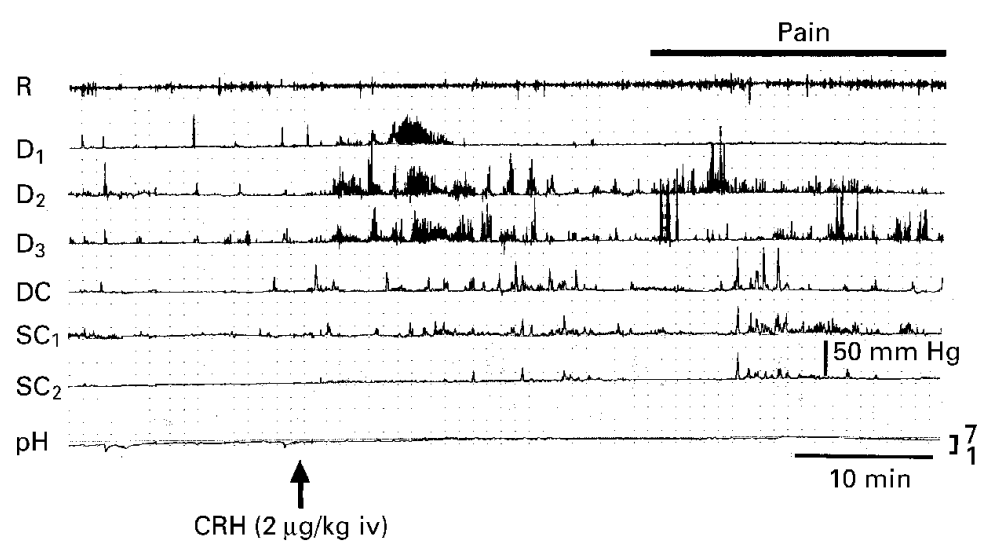

Figure 2 Manometric findings of a patient with IBS. Abbreviations as for fig 1. Administration of CRH stimulated the colon, particularly the descending colon, and evoked duodenal phase III which was followed by phase II contractions. This patient complained of abdominal pain during the period expressed by a solid bar.

activity at a frequency of 11-13 per minute with the retrograde propagation. ${ }^{20}$ Duodenal $\mathrm{pH}$ was estimated by area under $\mathrm{pH} 7.0(\mathrm{pH} \cdot \mathrm{sec})$ divided by duration of periods $(15 \times 60 \mathrm{sec})$. Frequency and duration of abdominal pain or discomfort were calculated from the event marks. The stored samples were defrosted and levels of plasma ACTH and serum cortisol were measured by radioimmunoassay. The minimal detectable value and interassay variability were as follows: ACTH, minimum $4 \mathrm{pg} / \mathrm{ml}$, variability $3.89 \%$; cortisol, minimum $0.64 \mathrm{mg} / \mathrm{dl}$, variability $2.64 \%$.

\section{STATISTICAL ANALYSIS}

Data were expressed as mean (SE) unless indicated otherwise. Means of two groups were compared by one way or two way analysis of variance (ANOVA). Post hoc analysis was carried out using Scheffe's $F$ test, $t$ tests, and nonparametric tests. Cross table analysis was used for qualitative data. A $\mathrm{p}$ value less than 0.05 was regarded as significant.

\section{Results}

PATTERNS OF GASTROINTESTINAL MOTILITY AND DUODENAL $\mathrm{pH}$

At baseline, there was no prominent difference in patterns in colonic or duodenal motility between controls and IBS patients. $\mathrm{CRH}$ induced segmental contractions in the descending and sigmoid colon within the first 15 minutes in controls (fig 1 ) and these responses

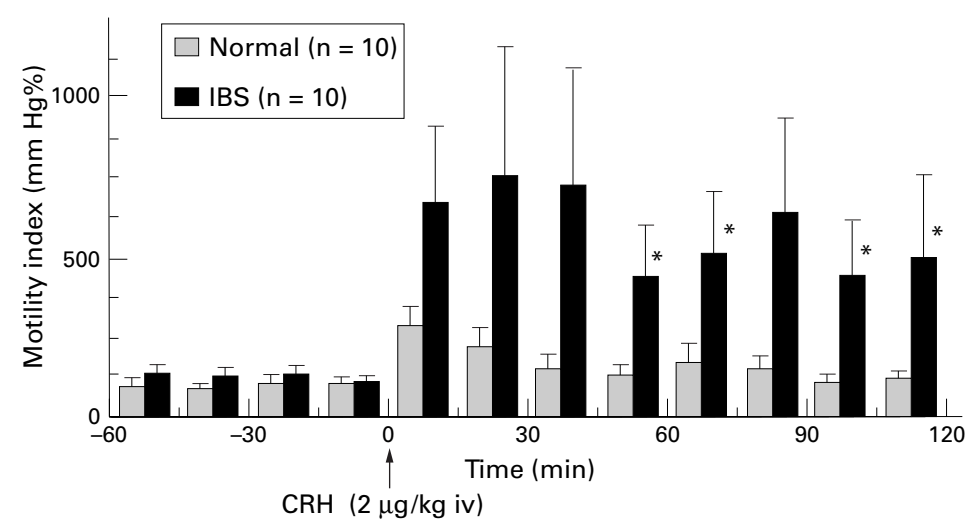

Figure 3 Changes in motility indexes of the descending colon induced by $C R H .{ }^{*}<<0.05$ versus controls by Mann-Whitney $U$ test.

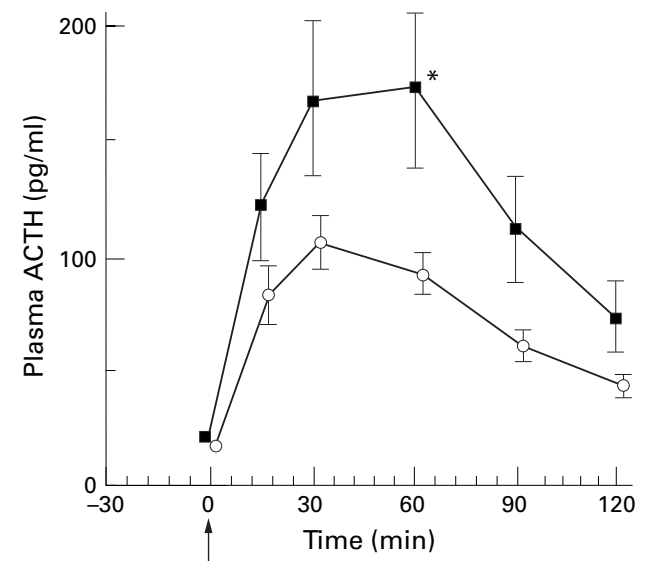

$\mathrm{CRH}(2 \mu \mathrm{g} / \mathrm{kg}$ iv $) \longrightarrow$
$\longrightarrow$ Normal $(\mathrm{n}=10)$
$\longrightarrow \operatorname{IBS}(\mathrm{n}=10)$

Figure 4 Effects of CRH on plasma $A C T H .{ }^{*} p<0.05$ versus controls by Scheffe $F$ test and Mann-Whitney $U$ test.

were prominent in IBS patients (fig 2). Phase III motor activity of the duodenum was significantly evoked by the CRH injection during the first 15 minutes in both groups $(p<0.05$; table 1). After CRH administration, IBS patients had a significantly higher incidence of duodenal dysmotility and longer duration of abdominal symptoms than controls $(\mathrm{p}<0.05$; table 1$)$. Duodenal $\mathrm{pH}$ was not changed by CRH.

CHANGES IN MOTILITY INDEXES OF THE COLON At baseline, there was no significant difference in motility indexes of the descending colon between controls (87.2 (29.3)) and IBS patients (101.3 (22.2)). CRH induced a significant increase in motility indexes of both groups (controls: 274.0 (72.6), IBS patients: 663.5 (251.6), $\mathrm{p}<0.001)$ and produced significantly higher motility indexes in IBS patients in controls $(p<0.05)$, especially in the later time periods (60-120 minutes) after administration of CRH (for example, during 45-60 minutes, controls: 118.1 (38.4) versus IBS patients: 430.4 (174.3), $\mathrm{p}<0.05$, fig 3 ). Motility indexes of two sites in the sigmoid colon showed the same pattern but the values were smaller than those of descending colon (data not shown). There was no significant correlation between duration of abdominal pain and colonic motility indexes.

NEUROENDOCRINE DATA

Basal levels of plasma ACTH were almost identical in both groups (controls: 20.4 (2.5) $\mathrm{pg} / \mathrm{ml}$ versus IBS patients: 23.3 (2.7) $\mathrm{pg} / \mathrm{ml}$ ). $\mathrm{CRH}$ induced a significant increase in plasma ACTH in both groups $(p<0.001)$ and produced significantly higher plasma ACTH in IBS patients than in controls $(p<0.01)$, especially at 60 minutes after administration (controls: 93.1 (9.2) $\mathrm{pg} / \mathrm{ml}$ versus IBS patients: 174.5 (35.1) pg/ml, p<0.05; fig 4).

Serum cortisol showed a significant increase after CRH and responses were identical in both groups (from baseline to peak value at $60 \mathrm{~min}-$ utes, controls: $13.6(1.2) \mathrm{mg} / \mathrm{dl}$ to 28.9 (1.3) $\mathrm{mg} / \mathrm{dl}$; IBS patients: $13.6(1.6) \mathrm{mg} / \mathrm{dl}$ to 30.2 (1.8) $\mathrm{mg} / \mathrm{dl}$; $\mathrm{p}<0.001)$. 
Discussion

This is the first study confirming that exogenous $\mathrm{CRH}$ can produce considerable changes in phasic contractions in human colon and small intestine. $\mathrm{CRH}$ is a peptide containing 41 amino acids, ${ }^{21}$ distributed in the whole brain with dense localisation in the paraventricular nucleus of the hypothalamus, ${ }^{22}$ and now considered to be a major mediator of the stress response. ${ }^{10}$ Stress releases CRH from the paraventricular nucleus and $\mathrm{CRH}$ stimulates pituitary ACTH secretion. ${ }^{23}$ Growing evidence from animal experiments indicates that endogenous CRH plays a role in mediating stress induced alteration of gastrointestinal motor function. ${ }^{6-9}$ Intracerebroventricular administration of CRH mimics the effects of various stressors in inhibiting small intestinal transit and stimulating colonic motor function through autonomic pathways in rats. ${ }^{6-9}$ Stress induced alterations in gastrointestinal motility in animals are abolished by intracerebroventricular administration of the $\mathrm{CRH}$ antagonist, $\alpha$ helical $\mathrm{CRH}_{9-41}{ }^{6-9}$ Our data provide strong support for the hypothesis of a role of CRH in alterations of human gastrointestinal motility.

The precise site of action of intravenous CRH on human gastrointestinal motility is unknown. Because intravenous administration of ACTH or $\beta$ endorphin does not mimic CRH effects on gut motility, ${ }^{5}$ increased plasma ACTH is not likely be involved in intestinal responses to CRH. There are three forms of CRH receptors: $\mathrm{CRH}_{1}, \mathrm{CRH}_{2 \alpha}$, and $\mathrm{CRH}_{2 \beta}{ }^{24}$ The mRNA for $\mathrm{CRH}_{1}$ and $\mathrm{CRH}_{2 \alpha}$ is predominantly expressed in the brain, whereas the mRNA for $\mathrm{CRH}_{2 \beta}$ is expressed in both the brain and the periphery. ${ }^{24}$ There are functional $\mathrm{CRH}$ receptors in the smooth muscle of the colon but the precise subtype of the receptors is unknown. ${ }^{25}$ As there is a specific unidirectional brain to blood transport system for $\mathrm{CRH},{ }^{26}$ non-specific penetration of intravenous $\mathrm{CRH}$ into the brain is unlikely to occur. ${ }^{23} \mathrm{~A}$ more plausible possibility is that intravenous $\mathrm{CRH}$ affects gut motility through brain $\mathrm{CRH}$ receptors at circumventricular organs that are relatively unprotected by the blood-brain barrier. ${ }^{27}$ This hypothesis is supported by the report that $\mathrm{CRH}$ given intracerebroventricularly and intravenously was essentially equipotent in modulating intestinal motility. ${ }^{9}$ In vitro effects of $\mathrm{CRH}$ on contractions of colonic smooth muscle cells are not excitatory but inhibitory. ${ }^{25}$ In contrast, in vivo effects of intracerebroventricular $\mathrm{CRH}$ on colonic motility is always excitatory. ${ }^{5-9}$ Therefore, altered gastrointestinal motility in our results is probably not mediated by peripheral receptors, but by central CRH receptors in the circumventricular organs. Administration of a specific antagonist would determine the precise sites and effects of intravenous CRH on gut motility.

Colonic motor function, of the descending colon in particular, was stimulated by $\mathrm{CRH}$ in our study. This finding is compatible with the results of animal experiments. ${ }^{7-9}$ The mechanism by which intracerebroventricular CRH influences colonic motility involves peripheral cholinergic neurotransmission. ${ }^{68}$ This neuro- transmission is probably mediated through the sacral parasympathetic pathways. ${ }^{8}$ Replicating previous reports, ${ }^{34}$ there is no significant difference in basal colonic motility between IBS patients and healthy control subjects in this study. In contrast, provocation tests such as loading psychological stress or injection of neostigmine are reported to induce colonic dysmotility in IBS patients. ${ }^{3}{ }^{4}$ These observations and our current data suggest that the colon of IBS patients is hypersensitive to acetylcholine and CRH which are presumably released by stress. Duodenal contraction was also induced by intravenous CRH in humans for a short duration. A significantly greater incidence of phase III within 15 minutes after $\mathrm{CRH}$ injection than that within 15 minutes of the start of baseline suggested that this is not incidental. Exogenous CRH induces a faster rhythm of the MMC period in the proximal jejunum in $\operatorname{dogs}^{28}$ and increases post-prandial motor activities in humans, ${ }^{29}$ suggesting its stimulatory action on motility of the small intestine in certain species. Prolonged ambulatory recording of duodenal motility showed that most IBS patients show increased incidence of clustered contractions under alert conditions. ${ }^{18}$ In our study, administration of $\mathrm{CRH}$ in IBS patients induced duodenal dysmotility with abdominal pain. These observations suggest that not only the colon but also the small intestine is sensitive to the centrally derived stimuli in IBS patients.

We found an increased ACTH response to $\mathrm{CRH}$ in IBS patients. Psychosocial stress induces onset and/or exaggeration of gastrointestinal symptoms in the majority of IBS patients. ${ }^{2-4}$ The responses of the hypothalamopituitary-adrenal axis during chronic stress in rats are characterised by increased hypothalamic CRH mRNA and immunoreactive CRH, decreased pituitary $\mathrm{CRH}$ receptors, higher pituitary content of ACTH, normal or slightly elevated plasma ACTH, and hypersecretion of the ACTH responses to a novel stress. ${ }^{30} 31$ Another study showed that pretreatment with short inescapable stress induced exaggerated ACTH secretion to a novel stress, whereas cortisol secretion did not differ between previously stressed and control rats. ${ }^{32}$ These results from stressed animals resemble our human data. Stress experience may account for a sensitised ACTH response in the pituitary gland and a desensitised adrenocortex of IBS patients. Furthermore, $\alpha_{2}$ adrenergic antagonists potentiate exogenous CRH induced ACTH secretion in rats. $^{33} \mathrm{~A}$ blunted growth hormone response to desipramine in IBS patients, which suggests impaired $\alpha_{2}$ adrenergic function, was also reported. ${ }^{34}$ Therefore, exogenous $\mathrm{CRH}$ induced ACTH hypersecretion in IBS patients may be due to $\alpha_{2}$ blockade in the brain. It is also possible that decreased levels of CRH binding protein, which inhibits the ACTH releasing properties of CRH, may play a role in ACTH hypersecretion in IBS patients. ${ }^{35}$ This possibility should be explored in the future.

Anxiety and depression are common psychological features in IBS patients. ${ }^{2}$ Intracerebroventricular administration of $\mathrm{CRH}$ or an $\alpha_{2}$ 
antagonist induces noradrenaline release in the locus caeruleus with concomitant production of anxiogenic behaviour in rats. ${ }^{22}$ Patients with depression have $\mathrm{CRH}$ hypersecretion in the brain, especially the paraventricular nucleus. ${ }^{36}$ Neuronal circuits relay visceral information to these nuclei. Distension of the distal colon increases the firing rate of the locus caeruleus. ${ }^{37}$ As the majority of IBS patients have a decreased visceral threshold to colonic distension, ${ }^{38}$ increased visceral information to the locus caeruleus may cause more activation of CRH neurones in the paraventricular nucleus. ${ }^{39}$ Exogenous CRH decreases the visceral threshold to rectal distension in humans ${ }^{40}$ and this mechanism probably relates to $\mathrm{CRH}$ induced abdominal symptoms in IBS patients as well as motility change. Furthermore, intravenous administration of CRH decreases slow wave sleep in humans ${ }^{11}$ and the proportion of rapid eye movement (REM) sleep is notably increased in IBS patients. ${ }^{41}$ We previously reported the stress induced increase in electroencephalographic beta power in IBS patients. ${ }^{4}$ These findings support our hypothesis that $\mathrm{CRH}$ is increased in the brain of IBS patients.

In conclusion, intravenous administration of CRH partially mimicked the stress response of the gastrointestinal motility and neuroendocrine response in humans. These responses were exaggerated in IBS patients. Our present study suggests that $\mathrm{CRH}$ plays an important role in modulating brain-gut functions under stress in humans, and that this neuropeptide relates to the pathophysiology of IBS.

Part of this work has been presented at the 95th annual meeting of the American Gastroenterological Association, 1994, New Orleans, Louisiana, USA (Gastroenterology 1994;106:A501). This research was supported by Grant-in-Aid for Scientific Research No. 2-603-6263-06770047 and No. 2-603-623105770042 from the Ministry of Education, Science, and Culture of Japan. The authors thank the following doctors for their comments and technical support: M Satake, M Kanazawa, T Sugawara, Y Endo, T Shoji, K Karahashi, T Imai, Y Tanno, and Sugawara,
A Utsumi.

1 Malagelada J-R. The gastroduodenal response to stress in man in health and functional dyspepsia. In: Tache Y, Wingate $\mathrm{D}$, eds. Brain-gut interactions. Boca Raton, Florida: CRC Press, 1991:297-305.

2 Drossman DA, Richter JE, Talley NJ, et al. The functional gastrointestinal disorders. Boston: Little, Brown and Co., 1994.

3 Fukudo S, Suzuki J. Colonic motility, autonomic function, and gastrointestinal hormones under psychological stress on irritable bowel syndrome. Tohoku f Exp Med 1987;151: on irrita $373-85$.

4 Fukudo S, Nomura T, Muranaka M, et al. Brain-gut response to stress and cholinergic stimulation in irritable response to stress and cholinergic stimulation in irritable

5 Williams CL, Villar RG, Peterson JM, et al. Stress-induced changes in intestinal transit in the rat: a model for irritable changes in intestinal transit in the rat: a model for

6 Lenz HJ, Raedler A, Greten H, et al. Stress-induced gastrointestinal secretory and motor responses in rats are mediated by endogenous cortocotropin-releasing factor. Gastroenterology 1988;95:1510-17.

7 Gue M, Junien JL, Bueno L. Conditioned emotional response in rats enhances colonic motility through the central release of corticotropin-releasing factor. Gastroenterology 1991;100:964-70.

8 Monnikes H, Schmidt BG, Tache Y. Psychological stressinduced accelerated colonic transit in rats involves hypothalamic corticotropin-releasing factor. Gastroenterology 1993;104:716-23.

9 Williams CL, Peterson JM, Villar RG, et al. Corticotropinreleasing factor directly mediates colonic responses to ress. Am $\mathcal{f}$ Physiol 1987;253:G582-6.

10 Dunn AJ, Berridge CW. Physiological and behavioral responses to corticotropin-releasing factor administration: is CRF a mediator of anxiety or stress responses? Brain Res is CRF a mediator of
$\operatorname{Rev} 1990 ; 15: 71-100$.

11 Holsboer F, von Bardeleben U, Steiger A. Effects of intravenous corticotropin-releasing hormone upon sleeprelated growth hormone surge and sleep EEG in men. Neuroendocrinology 1988;48:32-8.
12 Thompson WG, Creed F, Drossman DA, et al. Functional bowel disease and functional abdominal pain. Gastroenterol Int 1992;5:75-91.

13 Agreus L, Svardsudd K, Nyren O, et al. Irritable bowel syndrome and dyspepsia in the general population: overlap and lack of stability over time. Gastroenterology 1995;109: 671-80.

14 Lemann M, Flourie B, Picon L, et al. Motor activity recorded in the unprepared colon of healthy humans. Gut 1995;37:649-53.

15 Suda $\mathrm{T}$, Tomori N, Yajima F, et al. Immunoreactive corticotropin-releasing factor in human plasma. $\mathcal{f}$ Clin Invest 1985;76:2026-9.

16 Hermus ARMM, Pieters GFFM, Willemsen JJ, et al. Hypotensive effects of ovine and human corticotrophin-releasing factors in man. Eur 7 Clin Pharmacol 1987;31:531-4.

17 Bazzocchi G, Ellis J, Villanueva-Meyer J, et al. Postprandial colonic transit and motor activity in chronic constipation. Gastroenterology 1990;98:686-93.

18 Kellow JE, Gill RC, Wingate DL. Prolonged ambulant recordings of small bowel motility demonstrate abnormality in the irritable bowel syndrome. Gastroenterology 1990;98:1208-18.

19 Kellow JE, Phillips SF. Altered small bowel motility in irritable bowel syndrome is correlated with symptoms. Gastroenterology 1987;92:1885-93.

20 Stanghellini V, Camilleri M, Malagelada J-R. Chronic idiopathic intestinal pseudo-obstruction: clinical and intestinal manometric findings. Gut 1987;28:5-12.

21 Vale W, Spiess J, Rivier C, et al. Characterization of a 41-residue ovine hypothalamic peptide that stimulates secretion of corticotropin and $\beta$ endorphin. Science 1981;213:1394-7.

22 Petrusz P, Merchenthaler I. The corticotropin-releasing factor system. In: Nemeroff CB, ed. Neuroendocrinology. Boca Raton, Florida: CRC Press, 1992:129-83.

23 Owens MJ, Nemeroff CB. Physiology and pharmacology of corticotropin-releasing factor. Pharmacol Rev 1991;43: 425-73.

24 Lovenberg TW, Chalmers DT, Liu C, et al. $\mathrm{CFR}_{2 a}$ and $\mathrm{CRF}_{2 \beta}$ receptor mRNAs are differentially distributed between the rat central nervous system and peripheral tissues. Life Sci 1997;60:857-64.

25 Iwakiri Y, Chijiiwa Y, Motomura Y, et al. Presence of functional receptors for corticotropin-releasing hormone in caecal circular smooth muscle cells of guinea pig. Life Sci 1997;60:857-64.

26 Martins JM, Kastin AJ, Banks WA. Unidirectional specific and modulated brain to blood transport of corticotropinand modulated brain to blood transport of corticotropin-

27 Perrin MH, Donaldson CJ, Chen R, et al. Cloning and functional expression of a rat brain corticotropin-releasing factor (CRF) receptor. Endocrinology 1993;133:3058-61.

28 Bueno L, Fargeas MJ, Gue M, et al. Effects of corticotropinreleasing factor on plasma motilin and somatostatin levels and gastrointestinal motility in dogs. Gastroenterology 1986; 91:884-9.

29 Mayer EA, Sytnik B, Reddy SN, et al. Corticotropinreleasing factor (CRF) increases post-prandial duodenal motor activity in humans. Neurogastroenterol Motil 1992;4: $53-60$

30 Tizabi Y, Aguilera G. Desensitization of the hypothalamicpituitary-adrenal axis following prolonged administration of corticotropin-releasing hormone or vasopressin. Neuroendocrinology 1992;56:611-18.

31 Young EA, Akil H. Corticotropin-releasing factor stimulation of adrenocorticotropin and $\beta$-endorphin release: effects of acute and chronic stress. Endocrinology 1985;117: 23-30.

32 van Dijken, de Goeji DCE, Sutanto W, et al. Short inescapable stress produces long-lasting changes in the brainpituitary-adrenal axis of adult male rats. Neuroendocrinology 1993;58:57-64.

33 Kovacs K, Makara GB. Factors from the paraventricular nucleus mediate inhibitory effect of alpha-2-adrenergic drugs on ACTH secretion. Neuroendocrinology 1993;57: 346-50.

34 Dinan TG, Barry S, Ahkion S, et al. Assessment of central noradrenergic functioning in irritable bowel syndrome using a neuroendocrine challenge test. $f$ Psychosom Res 1990;34:575-80.

35 Behan DP, De Souza EB, Lowry PJ, et al. Corticotropinreleasing factor (CRF) binding protein: a novel regulator of $\mathrm{CRF}$ and related peptides. Front Neuroendocrinol 1995;16: 362-82.

36 Nemeroff CB. New vistas in neuropeptide research in neuropsychiatry: focus on corticotropin-releasing factor. Neuropsychopharmacology 1992;6:69-75.

37 Elam M, Thoren P, Srensson TH. Locus ceruleus neurons and sympathetic nerves: activation by visceral afferents. Brain Res 1986;375:117-25.

38 Mayer EA Raybould HE. Role of visceral afferent mechanisms in functional bowel disorders. Gastroenterology 1990;99:1688-704

39 Tache Y, Monnikes H, Bonaz B, et al. Role of CRF in stressrelated alterations of gastric and colonic motor function. Ann N Y Acad Sci 1993;697:233-43.

40 Lembo T, Plourde V, Shui Z, et al. Effects of the corticotropin-releasing factor (CRF) on rectal afferent corticotropin-releasing factor (CRF) on rectal afferent
nerves in humans. Neurogastroenterol Motil 1996;8:9-18.

41 Kumar D, Thompson PD, Wingate DL, et al. Abnormal REM sleep in the irritable bowel syndrome. Gastroenterology 1992;103:12-17. 